proceed therefrom by natural selection and by infinite permutations in infinite time. In other words, separate acts of creation are not necessary to produce species, and it is just possible not even genera. Darwin's colossal idea does not necessarily clash with that of a creative agency-it simply regards creation as a progressive rather than a finished work.

External conditions, in Darwin's opinion, modify in the fulness of time both plant and animal, and both advance in the scale of being-i.e., plants and animals improve upon their former selves, the fittest always surviving. Darwin's law of the "survival of the fittest" affords another illustration of the interaction of the natural forces, for it shows that climatic, geological, and other physical changes modify the form and functions of plants and animals-in other words, modify and alter within certain limits the form and constitution of organic beings.

Darwin's hypothesis has thrown much light upon the complicated questions of natural affinity, the homologies of organs in various animals, and the recurrence in the embryos of the higher animals of structural peculiarities found in the lower ones. It has connected as by a silver thread the various paleontological forms in time and the several faunas and floras in space. It has endeavoured to establish an actual genealogy and consanguinity of organisms. As time advances, fresh links binding apparently irreconcileable types together are found, and in the old geological records of the past the actual transitional forms may be traced.

Few in the present day will doubt that many of the forms regarded by naturalists as distinct species of the same genus were originally derived from the same primitive form; but the major question is still sub judice. It is not yet determined that "all mammals are derived from one original marsupial, all vertebrates from a primitive lancelet, and all plants and animals from the slimy protoplasm of a protiston." If, however, this should be proved at some future period to be the case, it will simply have the effect of reducing the number of separate creations; it will not obliterate our belief in a great First Cause. It will neither impeach nor impugn the power of the Creator; still less will it disprove his continued operation through eternal and immutable laws.

Gentlemen, I fear I have trespassed equally upon your time and patience. The subject, however, chosen for this my introductory lecture demanded consecutive treatment. I could not consistently treat of the materials and forces employed in the organisation of plants and animals, and omit the great modern doctrine of " natural selection." The points which I have endeavoured to illustrate in the course of my observations are these:-

Firstly. That organic and inorganic matter are correlated and interact.

Secondly. That the vital and physical forces are correlated and interact.

Thirdly, and lastly. That living organisms cannot be produced from purely inorganic matter by purely physical forces.

I have only attempted a rough sketch. To-morrow and throughout the winter session I shall endeavour faithfully to fill in the details. Those details are very numerous and very complicated, but, to my way of thinking, very beantiful; and if I can only succeed in creating within you the same enthusiasm which animates myself, I am not without a hope that the finished work will turn out a labour of love.

\section{A NEW CLASSIFTCATION OF INSANITY.}

\section{BY JOHN CHARLES BUCKNILL, F.R.S.,} zORD CHANCELLOR'S VISITOR ON LUNATICS.

Althougn this subject has been treated with great learning and judgment by Dr. Daniel Hack Tuke in the Manual of Psychological Medicine, yet, considering the different kinds, forms, or species of insanity, I have failed to find all the assistance which $I$ hoped for from some one or other of the existing systems of classification, especially in regard to treatment. Several of these systems are highly instructive on certain points-either, for instance, as to the psychical varieties, or the physical forms, or the pathological conditions, or, lastly, the natural groups, a small number of which undoubtedly do exist. Still I have not been able to find any one system which embraces all or nearly all the considerations which must be regarded in treatment. In this dilemma I was first tempted to state objections to the work which others have done, and especially to criticise the system of natural groups which has been most elaborated by my lamented friend the late Dr. Skae. But on reconsideration I have thought that, instead of finding fault with work which, however imperfect, is of undoubted value from one point of view, it would be more useful, if not more generous, to endeavour to construct a system of my own, which might more fully answer the purpose for which we needed it-namely, as a nosological scaffolding of form for the guidance of treatment.

My objections to the etiological system of classification I have stated at length in a review of Morel's classification; and they apply in the main to Skae's similar but more elaborate one, which has been designated by Dr. Clouston, its able expositor, as a system founded upon the principle of "the exclusion of everything mental or psychical connected with insanity." +

Without quoting these objections, I have the authority of the greatest intellect which has adorned our specialitythat of Griesinger-that "all classifications of insanity must again, in the end, come back to the principal psychological forms of mania, melancholia, and dementia, because they are actually founded in nature." M Moreover, the same high authority, in his introductory lecture, republished in the Journal of Mental Science (No. 48, p. 531), says:"This consideration of mental diseases, from a psychological point of view, is both necessary and serviceable to a firm and cunstant connexion with the other aspect of the subject"-namely, its relation to practical medicine, and over and over again he points out that, in order to arrive at a practical diagnosis for the purpose of treatment, we must consider the psychical with the physical symptoms and the etiology. "The real problem for solution is to determine not merely the character of the mental aberration, but, as far as possible, the nature of the lesion of the brain and of the nerves." In the classification of insanity there are some forms, he says, which, in framing our divisions, we must refer to the psychical characters alone, for they are deficient in all other symptoms, but in other cases we are not bound to adopt this course alone. He appears fully to have recognised the principle, although he did not attempt to carry it into effect, that the classification of insanity should be made to depend upon a combination of the psychical characters and of the pathological conditions.

The novelty of the scheme of classification now proposed consists in the combination of psychical characters or phenomena with pathogenetic relations and pathological conditions; the first forming the Classes, the second the Orders and Genera, and the third the Species.

Since the etiological classifications of Van der Kolk, Morel, and Skae have been published, a most important step, in my opinion, has been taken in advance by the pathological classification of Dr. Batty Tuke; but even this thoughtful writer entirely omits all consideration of mental symptoms, and such an omission in a classification of mental diseases, seems to me somewhat like the omission of flowers and foliage in a botanical system.

In the formation of classes I have followed Griesinger's simple division into states of psychical depression, psychical exaltation, and psychical debility; substituting, however, the conventional and now thoroughly established terms of Melancholia, Mania, and Dementia.

$X$ bave reversed the usual order of mania and melancholia, becau.se I believe that melancholia is the dominant psychical condition, and that Guislain was only wrong in being too exclusive in his theory that prenalgie was the source of all phrenesie. Idiocy I have relegated to a sub-class. Pinel included it in dementia, and it was only separated therefrom

* Journal of Mental Science, No. 38, p. $286 . \quad+$ Ibid., No. 87, p. 343. \$ Die Pathologie und Therapie, \&c., p. 121. 
by Esquirol. Pathologically, the distinction between primary and secondary dementia is at least as great as between brain-defect occurring before and after infancy. Crelinism is not congenital but toxic dementia.

The foundation of the orders and genera on pathogenetic relations is no doubt a natural one, and I think it can scarcely fail to be practically useful by impressing on the mind the kind of relation which the mental disease has with the bodily condition ; for the treatment of the patient, both as to mind and body, must necessarily depend to a very great extent upon this relation.

I do not presume to think that I have enumerated all the genera which, eventually, it may be found desirable to distinguish; and am well aware that the correctness of the position which I have assigned to some of the genera in the orders is quite open to discussion.

The inclusion of puerperal insanity in the Climacteric order is open to grave objection. This order, however, is intended to include vesanias which arise from or in conditions which are not pathological; and, although a deviation from bodily health generally precedes pnerperal insanit $y$, still the puerperal state can no more be considered necessarily a diseased state than that of puberty or old age. If there be a difficulty, the identification of species will resolve it, seeing that puerperal insanity may be septicæmic, anæmic, or neuralgic.

Of the Species there is little to say, except that the are the most important of all the divisions, and the most imperfect. Much has been left out which ought to have been admitted if knowledge had been sufficient. I trust, however, no condition has been admitted which ought to have been excluded.

Such conditions as are vaguely expressed by the Brunonian terms "sihenic" and "asthenic" have been omitted. The conditions of all the secreting organs have been omitted, simply from lack of sufficient knowledge; ind the excess or defect of irritability of the muscles, which form such marked features in mental disease, have been omitted for the same very unsatisfactory reason.

On the other hand, the consideration of abnormal cerebral conditions which have not hitherto been sufficiently regarded in nosologies have been introduced. The ill-understood but undisputed state in which either the brain or the nerves, or both, wear away their physiological powers without interruption or repose, and its reverse, I have designated by the terms hypertriptic and atriptic- $\tau \rho \in \iota \beta \omega$, to rub.

The hypertrophic and atrophic conditions of nutrition are well defined, if not yet well investigated; but the cacotrophic is a wide field of inquiry, in which ground has hardly yet been broken. Sclerosis of the brain and of the spinal column is cacotrophic. How many varieties of it are there? If there is a paresic variety, is there not also a syphilitic one, and, may be, some others? In this division into species I claim the aid of the microscopic and chemical pathologist, for upon it is founded the all-important question of ultimate diagnosis.

The field for clinical research is the correlation of the classes, species, and genera; but, even while this correlation is in process of being worked out, any concrete case of mental disease which is assigned to its proper place in the divisions of this system will have attributed to it a succession of characteristics which will scarcely fail to aid in the more systematic knowledge of its nature and the more definite aim of its treatment.

If it should be objected that this system is a complicated and artificial one, like the botanical system of Linnæus, the validity of the objection will be fully admitted, with the proviso that a complicated system is needful for complicated and ill-understood phenomena. With larger knowledge a more simple and more natural system will take its place.

CIAsses of Psychical Phenomena.

\section{Melancholia. \\ 2. Mania. \\ 3. Dementia.}

SUB-Crasses of Psychical Combinations and Transmutations.

1. Nelancholia, simple.

2. " combined with excitement.

3. " " with stupor (dementia attonita).

4. " mania, and dementia alternating (folie circulaire).
5. Mania, simple.

6. ,, with depressing emotions.

7., intercurrent with melancholia.

8. ", ," dementia.

9. " alternating with sanity (recurrent mania).

10. Dementia, simple and primary.

11. ", consecutive on mania or melancholia.

12. " congenital. Idiocy and imbecility.

ORDERs of Pathogenetic Relations.

1. Simple insanity. Idio-encephalic.

2. Allied insanity.

3. Sequential insanity.

4. Concurrent insanity.

5. Egressing insanity.

6. Metastatic insanity.

7. Climacteric insanity.

GeNera of Pathogenetic Relations.

Simple Insanity :

1. Insanity from hereditary predisposition.

2 , moral influences.

3.,$\quad$ intellectual overwork.

4., direct cerebral injuries.

5. Insanity of general paralysis (encephalo-rachitis).

Allied Insanity, influenced by other diseases, but independent :

1. Insanity with cardiac disease.

2. ", pulmonary disease, emphysema,

phthisis, \&c.

4. " " renal and visceral disease, \&c.

Sequential Insanity, caused by other disease which has subsided :

1. Insanity following idiopathic and exanthematous fevers.

2. Insanity following inflammations, as pneumonia.

3. ", injuries to the cerebro-spinal axis, apoplexies, \&c.

Concurrent Insanity, caused by other diseases or diseased conditions which continue to exist:

1. Insanity from ca- 3. Insanity from chorea. chexias - syphilitic, 4. ", alcoholism. chlorotic, cretinic, \&c. $5 . \quad$, masturba. Insanity from epilepsy.

6.

tion.

starvation.

Egressing Insanity, growing out of the former disease, of which it is an exaggeration :

1. Insanity egressing from hysteria,

$2 . "$ " ecstasy.

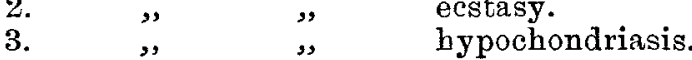

Metastatic Insanity, from the shifting or ceasing of other disease or suppression of discharges:

1. Insanity from rheumatism.

$2 . \quad$ erysipelas and skin diseases.

3. " suppression of habitual discharges,

hæmorrhoids, or ulcers.

4. , suppression of the catamenia.

Climacteric Insanity, caused by natural conditions of development and decline:

1. Insanity of the pregnant and puerperal state.

$2 . \quad, \quad$ pubescence.

3. $\quad$ " $\quad$ climacteric decline.

$4 . \quad$ old age.

SPECIES of Pathologica? Conditions differentiating the Genera by Pathological Conditions of the Brain and Nerves of the Blood and the Nutrition.

Neurotic:
1. Hyperæsthetic.
2. Anæsthetic
3. Neuralgic.
4. Sympathetic.
5. Apathetic.
6. Hypertriptic.
7. Atriptic.
Homic :
8. Hyperæmic.
. Anæmic.
10. Septicamic.
11. Uræmic.
12. Toxic
rophie
13. Hypertrophic.
14. Atrophic.
15. Cacotrophic or cachectic. 